\title{
Levantamento Florístico e Fitossociológico em Área de Caatinga Manipulada Durante o Período Chuvoso
}

Alano Albuquerque Luna ${ }^{1}$, Maria Socorro de Souza Carneiro ${ }^{1}$, Rafael Nogueira Furtado ${ }^{1}$, Gustavo Jorge Gonçalves Menezes Silva ${ }^{1}$, Mônica Matoso Campanha², Henrique Rocha de Medeiros ${ }^{3}$

Resumo: Este trabalho teve como objetivo verificar a variação no número de indivíduos e número de espécies ao longo do período chuvoso e verificar com o passar dos meses quais espécies prevaleceram em área pastejada por caprinos. O trabalho foi realizado na fazenda experimental Crioula, da EMBRAPA Caprinos e Ovinos, localizada na zona fisiográfica do Sertão Cearense, município de Sobral, CE. O experimento foi realizado em uma área de 4,8 ha pastejada por um rebanho de 19 matrizes caprinas, onde foram lançadas vinte vezes a cada mês uma moldura (1,0 m x 0,25 m), para identificação do número de espécies, famílias e contagem do número de indivíduos por espécie em cada parcela. O número de parcelas amostradas foi suficiente para refletir a fitodiversidade do local estudado. Foram identificadas 15 famílias e 30 espécies ao longo do período chuvoso. A família que apresentou maior número de espécies foi Leguminoseae (8). As espécies com maiores densidades absoluta e relativa foram a Hyptis suaveolans (L.) Poit e Blainvillea rhomboidea Cass. A dominância de espécies de pouco ou nenhum valor forrageiro indicaram elevado nível de degradação da pastagem e o ciclo de vida efêmero de algumas espécies presentes na área afetou a composição florística ao longo do período chuvoso.

Palavras-chave: diversidade, épocas, herbáceo, semiárido

\section{Floristic and Phytosociological Survey in an Area of Caatinga Manipulated During the Rainy Season}

Abstract: The objective of this study was to conduct a floristic inventory of the herbaceous layer in an area of Caatinga grazed by goats during the rainy season. The study was conducted at the Experimental farm Creole, physical area of EMBRAPA Goats and Sheep, located in the physiographic zone of Hinterland Cearense, municipality of Sobral, CE. The experiment was conducted in an area of 4.8 ha grazed by a herd of 19 goats, where they were released twenty times each month a frame $(1.0 \mathrm{mx} 0.25 \mathrm{~m})$ to identification of species, families and was made counting the number of individuals per species in each plot. The number of plots sampled was sufficient to reflect the phytodiversity of site studied. We identified 15 families and 30 species during the rainy season. The family that had the greatest number of species was Leguminoseae (8). The species with the largest absolute and relative densities were Hyptis suaveolans (L.) Poit and Blainvillea rhomboidea Cass. The dominance of species of little or no forage value indicated high level of pasture degradation and ephemeral life cycle of some species present in the area changed the floristic composition during the rainy season.

Key words: diversity, age, herbaceous, semi-arid

\footnotetext{
${ }^{1}$ Universidade Federal do Ceará (alano_luna@hotmail.com)

${ }^{2}$ Empresa Brasileira de Pesquisa Agropecuária, Embrapa Milho e Sorgo

${ }^{3}$ Universidade Federal do Rio Grande do Norte
} 


\section{Introdução}

Tradicionalmente a exploração da Caatinga ainda se caracteriza por processos meramente extrativistas, onde a vegetação da Caatinga tem sido historicamente utilizada para forrageamento animal na exploração pastoril, porém, a periodicidade pluviométrica e a exploração da pecuária vêm provocando o desaparecimento de espécies forrageiras e consequentemente queda na qualidade do pasto (Leite et al., 1995). No caso da pecuária, o superpastejo de ovinos, caprinos, bovinos e outros herbívoros tem modificado a composição florística nativa, seja pela duração ou pela pressão de pastejo exercida. (Cândido et al., 2005).

Segundo Pereira Filho et al. (2007) a ação antrópica tem conduzido a vegetação da Caatinga a um processo de sucessão secundária, onde no estrato herbáceo, gramíneas como as milhãs (Brachiaria plantaginea e Panicum sp.), capim rabo de raposa ( Setária sp.) e capim panasco (Aristida setifolia H. B. K.), além de dicotiledôneas como, mata-pasto (Senna obtusifolia) bamburral (Hyptis suaveolans (L.) Poit), Malva branca (Sida cordifolia L.), feijão-de-rola (Phaseolus patyróides L.), centrosema (Centrosema $\mathrm{sp}$ ), erva-deovelha (Stylosanthes humilis), manda pulão ( Croton sp.), bredo (Amaranthus sp.) dentre outras, destacamse nesse cenário.

A falta de planejamento no uso dos recursos oferecidos neste bioma proporciona a fragmentação da cobertura vegetal (Araújo et al., 2010) em um ambiente tão pouco conhecido e complexo podendo levar o mesmo a um processo irreversível de degradação (Santana \& Souto, 2006).

Os estudos florístico e fitossociológico constituem importante ferramenta para o conhecimento da composição, estrutura e distribuição da vegetação em determinada área. Ambos têm fornecido informações importantes para a compreensão da dinâmica da vegetação da Caatinga. O conhecimento da flora do Bioma Caatinga permitirá oferecer subsídios para um provável sistema de manejo e conservação de áreas representativas deste bioma.

A composição florística da forragem produzida no extrato herbáceo sofre variações significativas em função do ano, da estação do ano, da localização e do tipo de caatinga, sendo este extrato a principal fonte de forragem para os ruminantes durante a estação chuvosa (Araújo Filho \& Crispim, 2002). A manipulação da vegetação lenhosa objetivando o incremento na disponibilidade de forragem altera este ambiente e suas relações ecológicas nos três extratos (herbáceo, arbustivo e arbóreo).

Embora existam alguns trabalhos avaliando a estrutura fitossociológica da Caatinga focados principalmente no extrato arbustivo-arbóreo, estes ainda não abordam satisfatoriamente a diversidade deste bioma em suas diferentes situações edafoclimáticos (agreste, sertão, cariri, seridó, carrasco, entre outros). Quando se buscam informações sobre o componente herbáceo da Caatinga constata-se que o conhecimento da riqueza, endemismo, distribuição geográfica e ecológica dessas plantas é ainda mais limitado apesar da grande riqueza de espécies e importante contribuição na biodiversidade deste bioma. Estudos desta natureza podem contribuir para se entender a dinâmica dessa comunidade, fornecendo informações inéditas para a conservação do bioma caatinga (Andrade et al., 2007).

Este trabalho teve como objetivo verificar a variação no número de indivíduos e número de espécies ao longo do período chuvoso e verificar com o passar dos meses quais espécies prevaleceram em área pastejada por caprinos.

\section{Material e Métodos}

O presente trabalho foi realizado na fazenda experimental Crioula, área física da EMBRAPA 
Rev. Cient. Prod. Anim., v.17, n.1, p.41-49, 2015

Caprinos e Ovinos, localizada na zona fisiográfica do Sertão Cearense, município de Sobral, CE, à margem da estrada Sobral-Groaíras, km 4. Geograficamente está localizada a $3^{\circ} 42^{\prime}$ de latitude Sul e $40^{\circ} 21^{\prime}$ de longitude Oeste, com uma altitude de 83 metros acima do nível do mar. O relevo dominante é o suave ondulado (declividade 3,0 a $8,0 \%$ ) e o ondulado (declividade de 8,0 a 115\%), formando pequenas elevações de topos arredondados, sendo os tipos de solo dominantes os litólicos distróficos, planossolos e brunos não-cálcicos. Segundo a classificação de Köppen, o clima na região é do tipo BShw', com estação chuvosa de janeiro a junho e precipitação média de $759 \mathrm{~mm}$. O experimento foi realizado no período de fevereiro a julho de 2009 , considerado a estação chuvosa.

A área experimental de 4,8 hectares é caracterizada por uma vegetação lenhosa em estádio inicial de sucessão secundária, apresentando três estratos distintos, arbóreo, arbustivo e herbáceo, sendo utilizada durante todo o ano pelo rebanho da EMBRAPA, o qual é composto por 19 matrizes da raça Anglo-Nubiana que utilizam exclusivamente a caatinga durante o período chuvoso, com trânsito livre entre a área de pastejo e o aprisco, onde encontram água e sal mineral à vontade.

Foi realizado o raleamento com preservação de aproximadamente 400 árvores por hectare e o rebaixamento da mata nativa, com objetivo de ampliar a disponibilidade de biomassa para pastejo.

Foram realizadas coletas mensais para identificação das espécies presentes na área. Para isso, utilizou-se uma moldura com dimensão de $1,0 \mathrm{~m}$ x $0,25 \mathrm{~m}$ que foi lançada 20 vezes aleatoriamente em toda a área de caatinga de maneira a contemplar toda a diversidade presente. Os cortes foram realizados nos meses de fevereiro a julho de 2009. Todas as espécies foram inicialmente identificadas por nome vulgar, com auxílio de mateiro de campo com experiência na região.
Para confirmação e classificação final dos indivíduos em nível de família, gênero e espécies, os mesmos foram encaminhados ao Herbário da Universidade Estadual Vale do Acaraú (UVA) localizada no município de Sobral. Após cada coleta as amostras foram pesadas e levadas ao laboratório para a identificação e contagem do número de indivíduos de cada espécie em cada amostra.

Para os táxons encontrados foram calculados os parâmetros fitossociológicos de densidade absoluta (DA), densidade relativa (DR), frequência relativa (FR), abundância relativa (ABR) e índice de valor de importância (IVI) segundo MuellerDombois \& Ellenberg (1974). Os cálculos foram efetuados pelo software Microsoft Excel 2000 versão 9.0 .

\section{Resultados e Discussão}

As espécies registradas em função do número de amostras foram representadas na curva do coletor para os meses de fevereiro, março, abril e maio (Figura 1). A curva de acumulação de espécies ou curva do coletor é uma técnica que surgiu da relação entre o número de espécies e o número de parcelas amostrais, sendo considerada de grande importância na caracterização de comunidades vegetais (Schilling \& Batista, 2008) e vem sendo extensivamente utilizada em estudos de fitossociologia com objetivo de indicar se o número de amostras estabelecidas foi adequado ou não para o conhecimento da população. Observou-se que o número de parcelas amostradas nos quatro meses foi suficiente para refletir a fitodiversidade local nos meses avaliados.

Observou-se (Figura 1) que no mês de fevereiro ocorreu aumento progressivo no número de espécies da primeira até a terceira parcela mantendo-se estável entre a terceira e quinta parcela, voltando a aumentar até a décima parcela, estabilizando-se a partir de então 
Rev. Cient. Prod. Anim., v.17, n.1, p.41-49, 2015

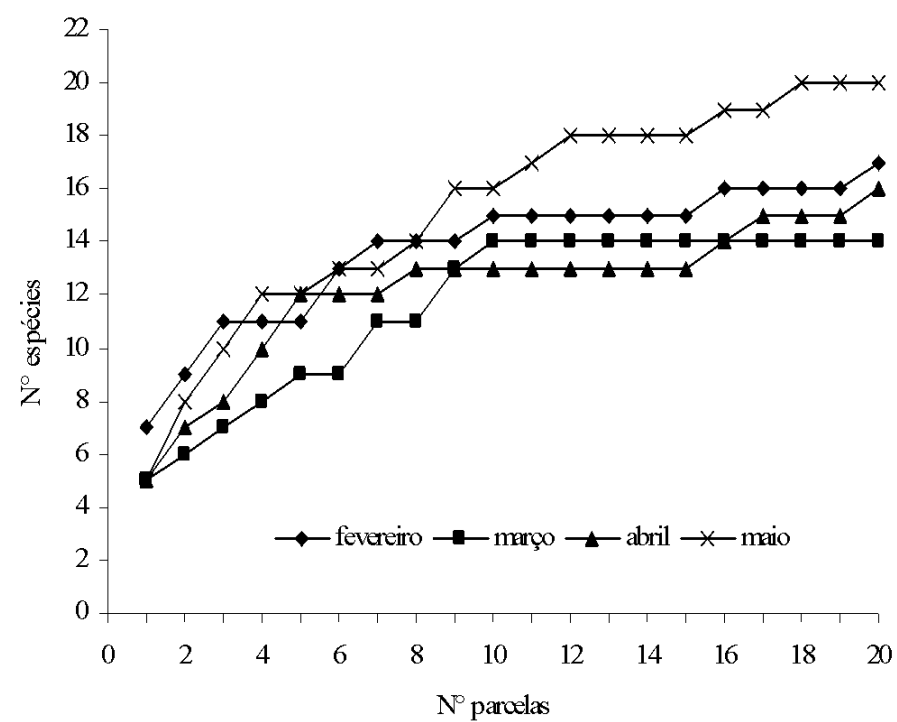

Figura 1. Curva de acumulação de espécies do extrato herbáceo para os meses de fevereiro, março, abril e maio, avaliados em área de caatinga manipulada no município de Sobral, Ceará

com surgimento de novas espécies apenas na décima sexta e vigésima parcelas.

Com relação a curva do coletor para o mês de março, observou-se crescimento no número de espécies da primeira até a décima parcela onde a partir desta não houve mais aparecimento de novas espécies. Para o mês de abril a curva do coletor mostra acréscimo de espécies até a quinta parcela, estabilizando-se entre a quinta e a sétima parcela, voltando a aparecer nova espécie na oitava parcela, estabilizando-se a partir desta até a décima quinta parcela com incremento de uma nova espécie na décima sexta, décima sétima e vigésima parcelas. Em maio o incremento no número de espécies foi constante com estabilização entre a décima segunda e décima quinta parcela e a partir da décima oitava parcela.

Normalmente as espécies que aparecem no final da curva são consideradas raras em decorrência da baixa densidade na população amostrada (Santana \& Souto, 2006) como é o caso da Bauhinia cheilantha

no mês de fevereiro e da Cloris gayana Kunth no mês de maio que apareceram com dois e um indivíduo nos respectivos meses. Estes resultados são esperados porque de acordo com Muniz et al. (1994) a curva do coletor nunca alcançará a assintótica porque sempre irão aparecer espécies novas mesmo em número reduzido. Sendo assim, a tendência a estabilização pode ser considerada suficiente para indicar o número mínimo de parcelas a ser utilizado (Santana \& Souto, 2006).

De acordo com o levantamento florístico realizado foram identificadas 15 famílias e 30 espécies ao longo dos 6 meses de avaliação (Tabela 1). Observouse maior diversidade nos meses finais do período chuvoso. De fevereiro a abril o número de famílias monitoradas manteve-se constante (9) elevando-se de maio até julho. Já o número de espécies foi inferior nos três primeiros meses, sendo que no mês de março registrou-se o menor número de espécies monitoradas (13), elevando-se em maio, junho e julho para 20, 21 e 19 respectivamente. Junho foi o mês que apresentou maior diversidade uma vez que foram amostradas 14 famílias e 21 espécies.

Resultados semelhantes foram relatados por Benevides et al. (2007) que identificaram 16 famílias e 32 espécies no componente herbáceo em área antropizada no ecossistema da caatinga e 20 famílias e 27 espécies em área semipreservada. Já Maracajá et al. (2003) e Araújo et al. (2010) avaliando o extrato arbustivo-arbóreo encontraram menor diversidade em ecossistemas de caatinga nos estados do Rio Grande do Norte e Paraíba respectivamente. Tais resultados confirmam os relatos de Araújo et al. (2007) ao afirmaram que o componente herbáceo no Bioma Tabela 1. Número de famílias e espécies monitoradas durante o período chuvoso em área de caatinga manipulada no município de Sobral, CE, 2009

\begin{tabular}{cccccccc}
\hline & Fevereiro & Março & Abril & Maio & Junho & Julho & Total \\
\hline Famílias & 9 & 9 & 9 & 10 & 14 & 14 & 15 \\
Espécies & 16 & 13 & 16 & 20 & 21 & 19 & 30 \\
\hline
\end{tabular}


Rev. Cient. Prod. Anim., v.17, n.1, p.41-49, 2015

Caatinga apresenta maior riqueza de espécies em relação ao extrato arbustivo-arbóreo.

Entre todas as famílias monitoradas, na área de estudo, a que apresentou maior número de espécies foi a família Leguminoseae com 8 espécies ao longo do período de avaliação, seguida das famílias Asteraceae e Poaceae com 3 espécies cada, Borraginaceae, Convolvulaceae, Euforbiaceae e Malvaceae com 2 espécies cada e as demais famílias contribuíram com uma espécie (Figura 2).

Resultados semelhantes foram observados por Andrade et al. (2009) trabalhando em áreas de caatinga na Paraíba sob diferentes níveis de conservação que constataram a presença das famílias Asteraceae, Convolvulaceae, Euphorbiaceae e Leguminoseae como as mais expressivas em número de espécies. Verificaram ainda, que nove famílias apresentaram apenas uma espécie respondendo por $42,8 \%$ do total das famílias identificadas. Resultado este, semelhante ao observado na presente pesquisa que apresentou oito famílias com apenas uma espécie durante o estudo o que representa 53,33\% do total de famílias monitoradas. Segundo Ratter et al. (2003) em áreas de cerrado com grande número de famílias representadas por apenas uma espécie,

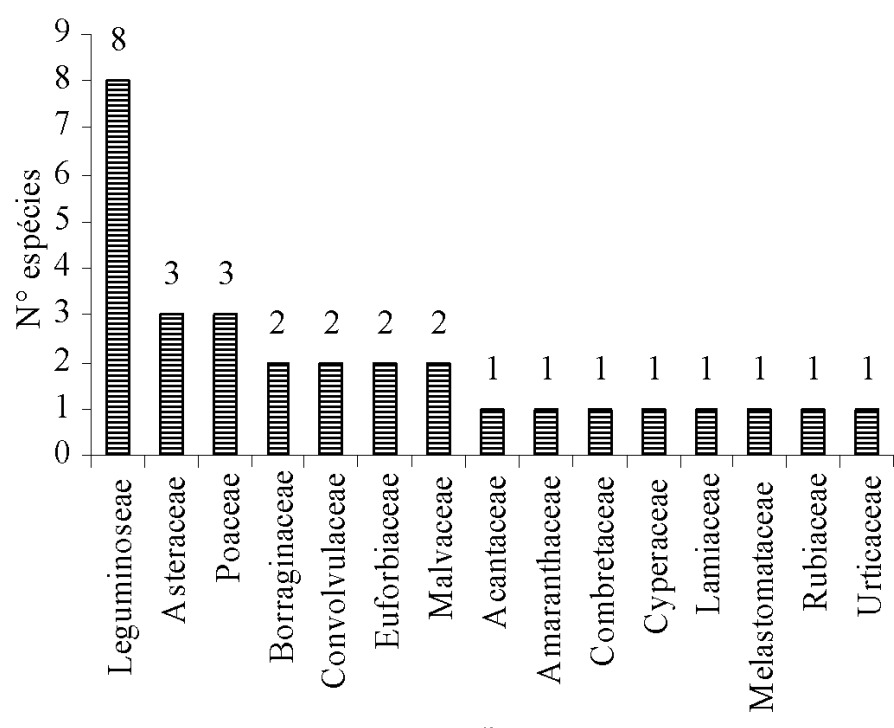

Familias

Figura 2. Número de espécies das famílias amostradas durante o período chuvoso em área de caatinga manipulada no município de Sobral, CE indica um padrão característico de locais de alta diversidade.

As espécies Bidens sp., Auxemma oncocalyx, Combretum leprosum Mart., Ipomoea sp., Hyptis suaveolans(L.) Poit, Clidemia hirta e Fleurya aestuans L. estiveram presentes em todo período de avaliação (Tabela 2). Por outro lado, observou-se que algumas espécies ocorreram apenas uma vez como a Borreria sp., Mimosa acutistipula Benth, Croton hemiargyreus e Panicum sp. Já Ruellia aspérula, Alternanthera brasiliana (L.) Kuntze, Cyperus rotundus L., Croton sp., Bauhinia cheilantha, Machaerium angustifolium Vog. e Sida cordifolia L. foram identificadas duas vezes durante todo o período chuvoso caracterizando assim a condição efêmera de grande parte das espécies presentes no extrato herbáceo da Caatinga.

Pinto (2008) realizando estudos sobre a composição florística do extrato herbáceo em cinco sítios ecológicos de Quixelô e Tauá no estado do Ceará, verificou como espécies dominantes Digitaria insularis (L.), Fodde, Commelina erecta L., Hyptis suaveolens (L.) Poit., Portulaca oleracea L., Ipomoea purpúrea (L.) Roth, Croton lundianus (Dierdr) Muell. Arg., Diodia saponarifolia (Cham \& Schltdl) K. Schum, Wissadula subpeltata (Kuntze) R. E. Fr., Eragrostis pilosa (L.) P. Beauv e Dactyloctenium aegyptium (L.) P. Beauv., com número de espécies e famílias superiores aos observados na presente pesquisa.

Na Tabela 3 consta os valores de densidade absoluta (DA) e relativa (DR) para todas as espécies monitoradas ao longo de todo o período chuvoso. Hyptis suaveolans (L.) Poit foi a espécie de maior participação na área avaliada de fevereiro a abril com redução em maio e julho. Blainvillea rhomboidea Cass. Também se destacou com elevada DA e DR de fevereiro a maio apresentando maiores DA e DR em maio reduzindo sua participação drasticamente em junho e não sendo identificada em julho. As elevadas 
Rev. Cient. Prod. Anim., v.17, n.1, p.41-49, 2015

Tabela 2. Famílias e espécies amostradas a cada mês durante o período chuvoso em área de caatinga manipulada no município de Sobral, CE

\begin{tabular}{|c|c|c|c|c|c|c|c|}
\hline \multirow{2}{*}{ Família } & \multirow{2}{*}{ Espécie } & \multicolumn{6}{|c|}{ Meses } \\
\hline & & Fev & Mar & Abr & Mai & Jun & Jul \\
\hline Acantaceae & Ruellia aspérula & & & & & $\mathrm{X}$ & $\mathrm{X}$ \\
\hline Amaranthaceae & Alternanthera brasiliana (L.) Kuntze & & & & & $\mathrm{X}$ & $\mathrm{X}$ \\
\hline \multirow{3}{*}{ Asteraceae } & Bidens sp. & $\mathrm{X}$ & X & $\mathrm{X}$ & X & X & $X$ \\
\hline & Blainvillea rhomboidea Cass. & $X$ & $X$ & $\mathrm{X}$ & $X$ & $\mathrm{X}$ & \\
\hline & Melanthera sp. & & & $\mathrm{X}$ & $\mathrm{X}$ & $\mathrm{X}$ & \\
\hline \multirow{2}{*}{ Borraginaceae } & Auxemma oncocalyx & $\mathrm{X}$ & $\mathrm{X}$ & $\mathrm{X}$ & $\mathrm{X}$ & $\mathrm{X}$ & $\mathrm{X}$ \\
\hline & Cordia alliodora & $\mathrm{X}$ & $\mathrm{X}$ & & $\mathrm{X}$ & $\mathrm{X}$ & $\mathrm{X}$ \\
\hline \multirow{3}{*}{ Combretaceae } & Combretum leprosum Mart. & $\mathrm{X}$ & $\mathrm{X}$ & $\mathrm{X}$ & $\mathrm{X}$ & $\mathrm{X}$ & $\mathrm{X}$ \\
\hline & Ipomoea sp. & $X$ & $X$ & $\mathrm{X}$ & $X$ & $\mathrm{X}$ & $\mathrm{X}$ \\
\hline & Quamoclit Rochae Hoehne & & $\mathrm{X}$ & $\mathrm{X}$ & $\mathrm{X}$ & & \\
\hline Cyperaceae & Cyperus rotundus $\mathrm{L}$. & & & & $\mathrm{X}$ & & $\mathrm{X}$ \\
\hline \multirow{2}{*}{ Euforbiaceae } & Croton hemiargyreus & & & & & $\mathrm{X}$ & \\
\hline & Croton sp. & & & & & $\mathrm{X}$ & $\mathrm{X}$ \\
\hline Lamiaceae & Hyptis suaveolans (L.) Poit & $\mathrm{X}$ & $\mathrm{X}$ & $\mathrm{X}$ & $\mathrm{X}$ & $\mathrm{X}$ & $\mathrm{X}$ \\
\hline \multirow{8}{*}{ Leguminoseae } & Bauhinia cheilantha & $\mathrm{X}$ & & & $\mathrm{X}$ & & \\
\hline & Caesalpinia pyramidalis Tul & $\mathrm{X}$ & & $\mathrm{X}$ & $\mathrm{X}$ & $\mathrm{X}$ & $\mathrm{X}$ \\
\hline & Desmodium canum (Gml.) Schinz et Thell. & $\mathrm{X}$ & & $\mathrm{X}$ & $\mathrm{X}$ & & \\
\hline & Machaerium angustifolium Vog. & & & & & $\mathrm{X}$ & $\mathrm{X}$ \\
\hline & Mimosa acutistipula Benth. & $\mathrm{X}$ & & & & & \\
\hline & Mimosa caesalpiniifolia & $\mathrm{X}$ & & $\mathrm{X}$ & & $\mathrm{X}$ & \\
\hline & Piptadenia macrocarpa & & & $\mathrm{X}$ & $X$ & $\mathrm{X}$ & $\mathrm{X}$ \\
\hline & Senna obtusifolia (L.) H.S. Irwin & $\mathrm{X}$ & $\mathrm{X}$ & $\mathrm{X}$ & $X$ & $\mathrm{X}$ & \\
\hline \multirow{2}{*}{ Malvaceae } & Sida cordifolia L. & & & & & $\mathrm{X}$ & $\mathrm{X}$ \\
\hline & Wissadula spicata & & & & & & $X$ \\
\hline Melastomataceae & Clidemia hirta & $\mathrm{X}$ & $\mathrm{X}$ & $\mathrm{X}$ & $\mathrm{X}$ & $\mathrm{X}$ & $\mathrm{X}$ \\
\hline \multirow{3}{*}{ Poaceae } & Brachiaria plantaginea & $\mathrm{X}$ & $\mathrm{X}$ & $\mathrm{X}$ & $\mathrm{X}$ & & \\
\hline & Cloris gayana Kunth & & & $\mathrm{X}$ & $X$ & $X$ & $X$ \\
\hline & Panicum sp. & & $\mathrm{X}$ & & & & \\
\hline Rubiaceae & Borreria sp. & & & & & $\mathrm{X}$ & \\
\hline Urticaceae & Fleurya aestuans L. & $\mathrm{X}$ & $\mathrm{X}$ & $\mathrm{X}$ & $\mathrm{X}$ & $\mathrm{X}$ & $\mathrm{X}$ \\
\hline
\end{tabular}

densidades destas duas espécies restringiram a participação de espécies com elevado valor forrageiro como Brachiaria plantaginea, Panicum sp., Ipomoea sp. e Sida cordifolia L.

Sizenando Filho et al. (2007) avaliando dois ambientes de caatinga sob diferentes níveis de antropização, destacaram Hyptis suaveolans (L.) Poit como uma das espécies com maior DA no ambiente mais antropizado. Com o fim do ciclo fenológico da Hyptis suaveolans (L.) Poit e Blainvillea rhomboidea Cass, outras espécies tiveram oportunidade de crescer e por consequência se tornaram espécies dominantes na pastagem, com destaque para Croton sp. em junho e Sida cordifolia L. em julho.
De modo geral, a DA total foi maior nos três primeiros meses avaliados, sendo março o mês de maior DA com um total de 540,2 indivíduos. $\mathrm{m}^{-2} \mathrm{e}$ em julho foi registrado a menor DA total com 73,6 indivíduos.m- $\mathrm{m}^{-2}$. Estes resultados mostram grande variação da composição florística ao longo do período chuvoso, corroborando com Albuquerque (1999) ao trabalhar com bovinos sob diferentes taxas de lotação em áreas de caatinga afirmou que a mortalidade das espécies arbustivas se deu mais em consequência da seca prolongada ocorrida no período experimental que pela intensidade de uso, mostrando que nem sempre a degradação é regida pelo antropismo, pois devem ser considerados também fatores abióticos, como o 
Tabela 3. Densidade absoluta (DA) e densidade relativa (DR) durante o período chuvoso em área de caatinga manipulada no município de Sobral, CE

\begin{tabular}{|c|c|c|c|c|c|c|c|c|c|c|c|c|}
\hline \multirow{2}{*}{ Espécie } & \multicolumn{6}{|c|}{ Densidade absoluta } & \multicolumn{6}{|c|}{ Densidade relativa } \\
\hline & Fev & Mar & Abr & Mai & Jun & Jul & Fev & Mar & Abr & Mai & Jun & Jul \\
\hline$\overline{\text { Ruellia aspérula }}$ & - & - & - & - & 10,8 & 7,4 & - & - & - & - & 7,23 & 10,05 \\
\hline Alternanthera brasiliana (L.) Kuntze & - & - & - & - & 1,0 & 1,6 & - & - & - & - & 0,67 & 2,17 \\
\hline Bidens sp. & 7,4 & 7,2 & 3,8 & 2,8 & 7,0 & 1,2 & 1,86 & 1,36 & 1,32 & 2,15 & 4,69 & 1,63 \\
\hline Melanthera sp. & - & - & 0,2 & 1,6 & 0,8 & - & - & - & 0,07 & 1,23 & 0,54 & - \\
\hline Auxemma oncocalyx & 1,0 & 2,2 & 1,8 & 0,8 & 1,2 & 0,8 & 0,25 & 0,41 & 0,62 & 0,61 & 0,80 & 1,09 \\
\hline Cordia alliodora & 2,6 & 2,0 & - & 0,2 & 1,2 & 1,4 & 0,65 & 0,37 & - & 0,15 & 0,80 & 1,90 \\
\hline Combretum leprosum Mart. & 2,6 & 2,2 & 8,0 & 1,8 & 2,8 & 2,4 & 0,65 & 0,41 & 2,77 & 1,38 & 1,87 & 3,26 \\
\hline Blainvillea rhomboidea & 38,6 & 134 & 91,8 & 43,4 & 2,4 & - & 9,68 & 24,81 & 31,81 & 33,28 & 1,61 & - \\
\hline Ipomoea sp. & 0,8 & 4,8 & 1,0 & 0,6 & 1,6 & 0,6 & 0,20 & 0,89 & 0,35 & 0,46 & 1,07 & 0,82 \\
\hline Quamoclit Rochae Hoehne & - & 0,2 & 1,0 & 1,8 & - & - & - & 0,04 & 0,35 & 1,38 & - & - \\
\hline Cyperus rotundus $\mathrm{L}$. & - & - & - & 34,8 & - & 0,6 & - & - & - & 26,69 & - & 0,82 \\
\hline Croton sp. & - & - & - & - & 49,8 & 11,2 & - & - & - & - & 33,33 & 15,22 \\
\hline Croton hemiargyreus & - & - & - & - & 2,6 & - & - & - & - & - & 1,74 & - \\
\hline Senna obtusifolia(L.) H.S. Irwin \& Barneby & 2,6 & 2,2 & 1,8 & 0,8 & 1,4 & - & 0,65 & 0,41 & 0,62 & 0,61 & 0,94 & - \\
\hline Bauhinia cheilantha & 0,4 & - & - & 0,6 & - & - & 0,10 & - & - & 0,46 & - & - \\
\hline Desmodium canum (Gml.) Schinz & 34,4 & - & 1,6 & 2,6 & - & - & 8,63 & - & 0,55 & 1,99 & - & - \\
\hline Mimosa caesalpiniifolia & 0,2 & - & - & 0,4 & - & 0,6 & 0,05 & - & - & 0,31 & - & 0,82 \\
\hline Hyptis suaveolans (L.) Poit & 275 & 328 & 155,4 & 10,8 & 43,2 & 5,8 & 68,99 & 60,72 & 53,85 & 8,28 & 28,92 & 7,88 \\
\hline Caesalpinia pyramidalis Tul & 0,4 & - & 0,8 & 0,4 & 0,2 & 0,6 & 0,10 & - & 0,28 & 0,31 & 0,13 & 0,82 \\
\hline Piptadenia macrocarpa & - & - & 0,4 & 0,6 & 0,4 & 0,8 & - & - & 0,14 & 0,46 & 0,27 & 1,09 \\
\hline Wissadula spicata & - & - & - & - & - & 0,6 & - & - & - & - & - & 0,82 \\
\hline Sida cordifolia $\mathrm{L}$. & - & - & - & - & 9,4 & 27 & - & - & - & - & 6,29 & 36,28 \\
\hline Clidemia hirta & 5,6 & 4,4 & 3,8 & 1,4 & 2,8 & 1,6 & 1,4 & 0,81 & 1,32 & 1,07 & 1,87 & 2,17 \\
\hline Brachiaria plantaginea & 18 & 31,2 & 11 & 0,2 & - & - & 4,52 & 5,78 & 3,81 & 0,15 & - & - \\
\hline Panicun & - & 8,6 & - & - & - & - & - & 1,59 & - & - & - & - \\
\hline Cloris gayana Kunth & - & - & 0,2 & 13 & 1,4 & 4,6 & - & - & 0,07 & 9,97 & 0,94 & 6,25 \\
\hline Borreria sp. & - & - & - & - & 2,2 & - & - & - & - & - & 1,47 & - \\
\hline Fleurya aestuans L. & 2,2 & 6,4 & 6 & 11,8 & 7,0 & 4,2 & 0,55 & 1,18 & 2,08 & 9,05 & 4,69 & 5,71 \\
\hline Mimosa acutistipula Bent & 0,4 & - & - & - & & - & 0,10 & - & - & - & - & - \\
\hline Machaerium angustifolium & - & - & - & - & 0,2 & 0,6 & - & - & - & - & 0,13 & 0,82 \\
\hline Total & 398,6 & 540,2 & 288,6 & 130,4 & 149,4 & 73,6 & 100 & 100 & 100 & 100 & 100 & 100 \\
\hline
\end{tabular}

clima, que tem grande influência sobre a vegetação, por Blainvillea rhomboidea e Fleurya aestuans principalmente, do extrato herbáceo.

L. Outras espécies que apresentaram elevadas

Hyptis suaveolans (L.) Poit foi a espécie que frequências relativas foram Brachiaria plantaginea apresentou maior frequência relativa (Tabela e Bidens sp em fevereiro, Blainvillea rhomboidea 4) de fevereiro a abril sendo superada em maio e Brachiaria plantaginea em março e Blainvillea Tabela 4. Frequência relativa (FA), Abundância relativa (ABR) e Índice de valor de importância (IVI) durante o período chuvoso em área de caatinga manipulada no município de Sobral, CE

\begin{tabular}{|c|c|c|c|c|c|c|c|c|c|c|c|c|}
\hline \multirow{2}{*}{ Espécie } & \multicolumn{4}{|c|}{ Frequência relativa } & \multicolumn{4}{|c|}{ Abundância relativa } & \multicolumn{4}{|c|}{ Índice de valor de importância } \\
\hline & Fev & Mar & Abr & Mai & Fev & Mar & Abr & Mai & Fev & Mar & Abr & Mai \\
\hline Bidens sp. & 10,57 & 6,92 & 8,47 & 2,73 & 1,88 & 2,83 & 2,03 & 6,45 & 14,31 & 10,63 & 11,82 & 11,34 \\
\hline Melanthera sp. & - & - & 0,85 & 4,59 & - & - & 1,07 & 2,21 & - & - & 1,98 & 8,02 \\
\hline Auxemma oncocalyx & 3,25 & 4,62 & 4,24 & 2,75 & 0,83 & 1,09 & 1,92 & 1,84 & 4,33 & 6,11 & 6,78 & 5,21 \\
\hline Cordia alliodora & 7,32 & 3,85 & - & 0,92 & 0,96 & 1,19 & - & 1,38 & 8,93 & 5,41 & - & 2,45 \\
\hline Combretum leprosum Mart. & 5,69 & 3,85 & 12,71 & 6,42 & 1,23 & 1,31 & 2,84 & 1,78 & 7,57 & 5,56 & 18,33 & 9,58 \\
\hline Blainvillea rhomboidea & 5,69 & 13,08 & 15,25 & 14,68 & 18,26 & 23,43 & 27,20 & 18,73 & 33,63 & 61,31 & 74,27 & 66,69 \\
\hline Ipomoea sp. & 3,25 & 6,92 & 1,69 & 2,75 & 0,66 & 1,59 & 2,67 & 1,38 & 4,12 & 9,40 & 4,71 & 4,59 \\
\hline Quamoclit Rochae Hoeh & - & 0,77 & 2,54 & 2,75 & - & 0,59 & 1,78 & 4,14 & - & 1,40 & 4,67 & 8,28 \\
\hline rotundus $\mathrm{L}$. & - & - & - & 9,17 & - & - & - & 24,03 & - & - & - & 59,89 \\
\hline tusifolia(L.) & 5,69 & 4,62 & 3,39 & 2,75 & 1,23 & 1,09 & 2,40 & 1,84 & 7,57 & 6,11 & 6,41 & 5,21 \\
\hline Bauhinia c & 0,81 & - & - & 2,75 & 1,32 & - & - & 1,38 & 2,24 & - & - & 4,59 \\
\hline Desmodiu & 7,32 & - & 4,24 & 6,42 & 12,66 & - & 1,71 & 2,56 & 28,60 & - & 6,50 & 10,28 \\
\hline Mimo & 0,81 & - & - & 1,83 & 0,66 & - & - & 1,38 & 1,53 & - & - & 3,52 \\
\hline Hyptis & 15,45 & 14,62 & 16,95 & 10,09 & 47,93 & 51,31 & 41,45 & 6,78 & 132,4 & 126,6 & 112,2 & 25,15 \\
\hline Caesalpini & 0,81 & - & 2,54 & 1,83 & 1,32 & - & 1,42 & 1,38 & 2,24 & - & 4,24 & 3,52 \\
\hline Piptad & - & - & 1,69 & 0,92 & - & - & 1,07 & 4,14 & - & - & 2,90 & 5,52 \\
\hline Cliden & 8,94 & 3,08 & 5,08 & 2,75 & 1,69 & 3,27 & 3,38 & 3,22 & 12,03 & 7,16 & 9,78 & 7,05 \\
\hline Brachic & 12,20 & 13,08 & 9,32 & 0,92 & 3,97 & 5,45 & 5,33 & 1,38 & 20,68 & 24,31 & 18,47 & 2,45 \\
\hline Panicur & - & 4,62 & - & - & - & 4,26 & - & - & - & 10,47 & - & - \\
\hline Cloris g & - & - & 0,85 & 10,09 & - & - & 1,07 & 8,16 & - & - & 1,98 & 28,22 \\
\hline Fleurya aes & 5,69 & 10,77 & 10,17 & 12,84 & 1,04 & 1,36 & 2,67 & 5,82 & 7,28 & 13,31 & 14,92 & 27,71 \\
\hline Mimosa acutistipula Benth. & 0,81 & 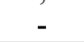 & - & - & 1,32 & - & - & - & 2,24 & - & 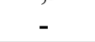 & 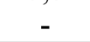 \\
\hline
\end{tabular}


Rev. Cient. Prod. Anim., v.17, n.1, p.41-49, 2015

rhomboidea e Combretum leprosum Mart. em abril. Quanto a abundância relativa (ABR), Hyptis suaveolans (L.) Poit se destacou com maiores valores de fevereiro a abril seguida por Blainvillea rhomboidea. Já no mês de maio, Cyperus rotundus L. apareceu com maior abundância relativa seguida por Blainvillea rhomboidea que foi a segunda espécie em abundância durante todo período de avaliação.

O índice de valor de importância (IVI) indica quais espécies são mais importantes dentro da área estudada. Por apresentar maiores valores de DR, FR e ABR, Hyptis suaveolans (L.) Poit constituiu-se na espécie de maior IVI de fevereiro a abril seguida por Blainvillea rhomboidea. Em maio Blainvillea rhomboidea, foi a espécie de maior IVI, seguida por Cyperus rotundus L., Cloris gayana Kunth e Fleurya aestuans L. A dominância de espécies de pouco ou nenhum valor forrageiro devido ao histórico de utilização da área para pastagem indicam um elevado nível de degradação.

\section{Conclusões}

Leguminoseae, Poaceae e Asteraceae compõem as famílias com maior número de espécies, sendo que as espécies Hyptis suaveolans (L.) Poit e Blainvillea rhomboidea Cass dominaram a área com maiores densidades absoluta e relativa, frequência relativa, abundância relativa e valor de importância.

Apesar do razoável número de espécies monitoradas, a dominância de espécies de pouco ou nenhum valor forrageiro no estrato herbáceo, indicaram elevado nível de degradação da pastagem.

Além da heterogeneidade de fatores climáticos, o ciclo de vida efêmero de algumas espécies presentes na área afetou a composição florística e fitossociológia ao longo do período chuvoso.

\section{Referências Bibliográficas}

ALBUQUERQUE, S.G. Caatinga vegetation dynamics under various grazing intensities by steers in the Semi-Arid Northeast, Brazil. Journal of Range Management, v. 52, p. 241-248, 1999.

ANDRADE, L.A.; OLIVEIRA, F.X.; NEVES, C.M.L.; FELIX, L.P. Análise da vegetação sucessional em campos abandonados no agreste paraibano. Revista Brasileira de Ciências Agrárias, v.2, n.2, p.135-142, 2007.

ANDRADE, M.V.M.; ANDRADE, A.P.; SILVA, D.S.; BRUNO, R.L.A.; GUEDES, D.S. Levantamento florístico e estrutura fitossociológica do estrato herbáceo e subarbustivo em áreas de caatinga no cariri paraibano. Revista Caatinga, v.22, n.1, p.229-237, 2009.

ARAÚJO FILHO, J.A.; CRISPIM, S.M.A. Pastoreio combinado de bovinos, caprinos e ovinos em áreas de caatinga no nordeste do Brasil. In: Conferência Virtual Global Sobre Produção Orgânica de Bovinos de Corte, 1, 2002, Concórdia. Anais... Concórdia: Embrapa pantanal, 2002, p. 1-7.

ARAÚJO, E.L.; CASTRO, C.C.; ALBUQUERQUE, U.P. Dynamics of Brazilian Caatinga: A Review Concerning the Plants, Environment and People. Functional ecology and communities, v.1, n.1, p.1528, 2007.

ARAUJO, K.D.; PARENTE, H.N.; SILVA, E.E.; RAMALHO, C.I.; DANTAS, R.T.; ANDRADE, A.P.; SILVA, D.S. Levantamento florístico do estrato arbustivo-arbóreo em áreas contíguas de Caatinga no cariri paraibano. Revista Caatinga, v.23, n. 1, p.63-70, 2010.

BENEVIDES, D.S.; MARACAJA, P.B.; SIZENANDO FILHO, F.A.; GUERRA, A.M.N.M.; PEREIRA, T.F.C. Estudo da Flora Herbácea da Caatinga no Município de Caraúbas-RN. Revista Verde da Agroecologia e Desenvolvimento Sustentável, v.2, n.1, p.33-44, 2007. 
CÂNDIDO, M.J.D; ARAÚJO, G.G.L.; de fitomassa do estrato herbáceo de uma caatinga CAVALCANTE, M.A.B. Pastagens no ecossistema raleada submetida ao pastejo alternado ovino-caprino. semiárido brasileiro: atualização e perspectivas Livestock Research for Rural Development, v.19, n.1, futuras. In: Reunião Anual da Sociedade Brasileira de p.190-202, 2007.

Zootecnia, 42, 2005, Goiânia. Anais... Goiânia: SBZ, PINTO, M.S.C. Levantamento florístico e composição 2005, p.85-94.

químico-bromatológica do estrato herbáceo em áreas

LEITE, E.R.; ARAÚJO FILHO, J.A.; PINTO, F.C. de Quixelô e Tauá Ceará. Fortaleza: Tese (Doutorado) Pastoreio combinado de caprinos com ovinos em Universidade Federal do Ceará, 2008. 120p. caatinga rebaixada: desempenho da pastagem e dos RATTER, J.A.; BRIDGEWATER, S.; RIBEIRO, J.F. animais. Pesquisa Agropecuária Brasileira, v.30, n.8, p. $1129-1134,1995$.

Analysis of the floristic composition of the brazilian MARACAJÁ, P.B.; BATISTA, C.H.F.; SOUSA, A.H.; VASCONCELOS, W.E. Levantamento florístico e fitosociológico do extrato arbustivo-arbóreo de dois ambientes na Vila Santa Catarina, Serra do Mel, RN. Revista de Biologia e Ciências da Terra. v.3, n.2, p.1$13,2003$. cerrado vegetation III: Comparison of the woody vegetation of 376 areas. Edinburg journal of Botany, v.60, n.1, p.57-109, 2003.

SANTANA, J.A.S.; SOUTO, J.S. Diversidade e estrutura fitossociológica da Caatinga na estação ecológica do Seridó-RN. Revista de Biologia e Ciências da Terra, v.6, n.2, p.232-242, 2006.

MUELlER-DOMBOIS, D.; ELLENBERG, H.A. SCHILlinG，A.C.; BATISTA, J.L.F. Curva de Aims and methods of vegetation ecology. New York: acumulação de espécies e suficiência amostral em John Wiley \& Sons, 1974. 547 p. florestas tropicais. Revista Brasileira de Botânica, MUNIZ, F.H.; CESAR, O.; MONTEIRO, R. v.31, n.1, p.179-187, 2008.

Fitossociologia da vegetação arbórea da Reserva SIZENANDO FILHO, F.A.; MARACAJA, P.B.; Florestal do Sacavém, São Luís, Maranhão (Brasil). DINIZ FILHO, E.T.; FREITAS, R.A.C. Estudo Acta Amazônica, v.24, n.3/4, p.219-236, 1994. floristico e fitossociológico da flora herbácea do PEREIRA FILHO, J.M.; ARAÚJO FILHO, J.A.; município de Messias Targino, RN/PB. Revista de CARVAlHO, F.C.; REGO, M.C. Disponibilidade Biologia e Ciências da Terra, v.7, n.2, p.95-101, 2007. 